\title{
Trace elements in the spinal cord and other tissues in motor neuron disease
}

\author{
JD MITCHELL, BW EAST,* IA HARRIS,* RJ PRESCOTT, $\dagger$ B PENTLAND \\ From the Department of Medical Neurology, University of Edinburgh, Edinburgh. Scottish Universities \\ Research and Reactor Centre,* East Kilbride, Glasgow. Medical Computing and Statistics Unit, Medical \\ School, $\uparrow$ Teviot Place, Edinburgh, UK
}

SUMMARY Trace elements were estimated in the spinal cord, liver and bone of five patients dying of motor neuron disease and five control subjects dying of non-neurological disease. The content of selenium in cord and liver and the cord manganese level were significantly increased in the motor neuron disease patients. These findings are discussed in terms of the possible aetiology of motor neuron disease.

Since the first description of motor neuron disease 150 years ago, ${ }^{12}$ the possible role of lead in its pathogenesis has been a source of controversy. Its recognition as a distinct clinical entity emerged from reports of patients showing features similar to those of lead poisoning but lacking a history of exposure. ${ }^{2-4}$ Although it is clear that motor neuron disease-like syndromes can be seen in both lead ${ }^{5-8}$ and mercury ${ }^{10}$ toxicity, such patients improve either with chelation therapy or removal from the contaminated environment. Patients with motor neuron disease do not and the significance of reports of increased lead levels in the spinal cord of patients dying of motor neuron disease ${ }^{1112}$ is uncertain. It seems likely that these represent a secondary rather than a primary effect. ${ }^{1213}$

The possibility remains that motor neuron disease arises as a result of a metabolic disturbance of motor neurons. The RNA content of motor neurons has been reported to be reduced ${ }^{14-16}$ and it has recently been suggested that these observations might reflect defective enzymatic DNA repair mechanisms. ${ }^{17}$ While this is an attractive hypothesis there is no direct supporting evidence. Trace elements are of crucial importance in metabolism, particularly in respect of

Address for reprint requests: Dr JD Mitchell, Department of Medical Neurology, Northern General Hospital, Ferry Rd, Edinburgh, EH5 2DQ, UK.

Received 14 December 1984. Accepted 14 January 1985 enzyme function. We have previously found the CSF cobalt level to be reduced in motor neuron disease patients as compared with a control group free of neurological disease. ${ }^{18}$ Acknowledging that CSF levels might not reflect tissue concentrations we estimated the content of a range of trace elements in spinal cord, liver and bone of patients dying of motor neuron disease compared with a control group dying of non-neurological disease.

\section{Methods}

\section{Subjects and sample preparation}

Specimens of spinal cord, liver and bone were obtained post mortem from five patients who had died of motor neuron disease and five control subjects who had died of nonneurological disease. The diagnoses of the control population are given in table 1 , and the clinical features of the motor neuron disease patients in table 2. The diagnosis of motor neuron disease was established in each case only after full in-patient investigation including appropriate blood tests and radiological studies, CSF examination and electrophysiological studies.

Segments of spinal cord measuring approximately $1 \mathrm{~cm}$ were taken at three levels, viz cervical, mid-thoracic and lumbar enlargement. The specimen of bone was a thoracic spinous process obtained during the removal of the cord. The liver specimen measured approximately $2 \mathrm{~cm} \times 1 \mathrm{~cm} \times 1$ cm. Stainless steel instruments (BS 2982, British Standards Institution 1974) were used to dissect the samples which were transferred immediately to metal-free plastic storage containers. They were not fixed but stored at $-20^{\circ} \mathrm{C}$ pending analysis. : 
Table 1 The control group-clinical features

\begin{tabular}{llll}
\hline Patient & $\begin{array}{l}\text { Age (at death) } \\
(y r)\end{array}$ & Cause of death & Other conditions \\
\hline 1 & 59 & Acute myocardial infarction & Pulmonary hamartoma \\
2 & 73 & Acute on chronic cardiac failure & Hypertension \\
3 & 68 & Acute myocardial infarction & Pulmonary thrombo-embolism \\
4 & 74 & Squamous cell carcinoma of oesophagus & Aspiration pneumonia. No metastasis outside \\
regional lymph nodes & Pulmonary thrombo-embolism \\
\hline
\end{tabular}

Table 2 The patient group-clinical features

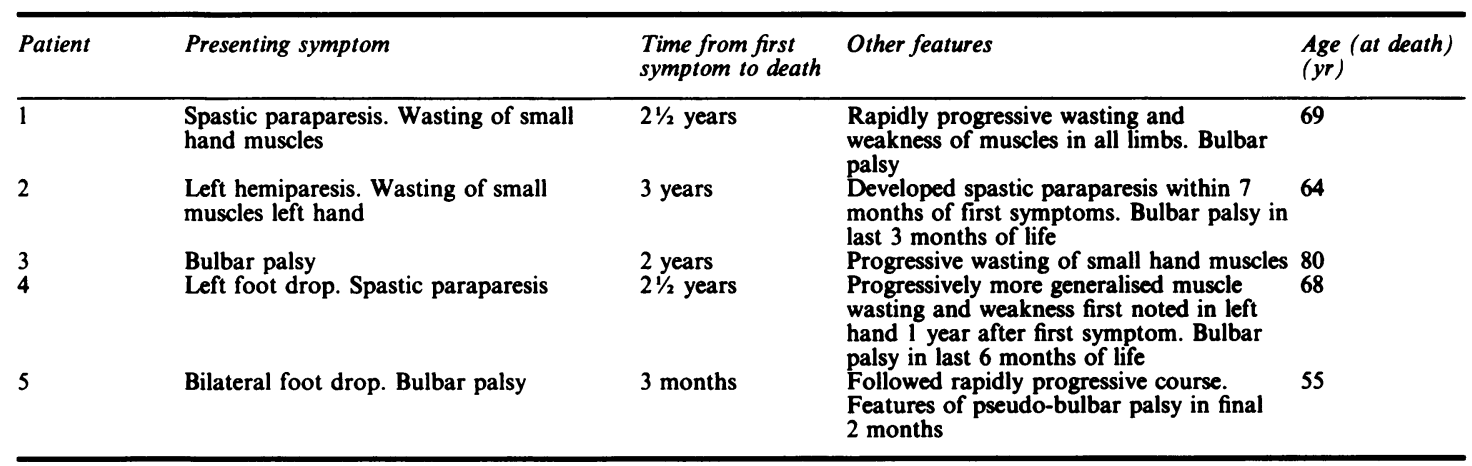

Analysis

The specimens were freeze-dried in a Chemlab SB30 freezedrier and then taken to the Scottish Universities Research and Reactor Centre where the content of a wide range of trace elements was estimated by in vitro neutron activation analysis. Those performing the analysis did not know whether individual specimens came from the patient or the control group. The specimens were subjected to a thermal neutron flux from the Argonaut UTR300 reactor for two periods. The first was a 2 minute exposure to a flux of $3 \times$ $10^{12}$ neutrons $\mathrm{cm}^{-2} \mathrm{~s}^{-1}$. Gamma emitting isotopes of sodium, potassium, chlorine, magnesium and manganese were formed as a result of this and the induced activity measured using an $80 \mathrm{~cm}^{3} \mathrm{Ge}-\mathrm{Li}$ detector. Gamma ray spectra were obtained by 4096 channel analysis and gamma peak count rates calculated using standard peak analysis and identification software. The samples were then exposed to a thermal flux of $10^{12}$ neutrons $\mathrm{cm}^{-2} \mathrm{~s}^{-1}$ for 54 hours. Following this irradiation gamma emitting isotopes of chromium, iron, cobalt, zinc, rubidium, caesium, selenium and antimony were formed. On this occasion the induced activity was counted using a $130 \mathrm{~cm}^{3} \mathrm{Ge}-\mathrm{Li}$ detector and the gamma ray spectra were recorded and gamma peak count rates calculated as before. This enabled the content of these trace elements within each sample to be measured.

\section{Statistical methods}

Tests of significance between the two groups were based on the Wilcoxon rank sum test. The content of the trace elements at the three cord levels were compared using the Friedman two-way analysis of variance by ranks. In the absence of differences, the readings from the three sites were combined by taking the geometric mean of the three obser- vations. Subsequent comparison of levels in the spinal cord between the control group and the motor neuron disease patients was then based on this combined measurement, rather than on the values from individual sites.

\section{Results}

The spinal cord manganese $(\mathrm{p}<0.01)$ and selenium $(p<0.01)$ levels were significantly increased in the motor neuron disease patients. These results are plotted in figs 1 and 2 respectively. The hepatic selenium content was also significantly increased $(p<0.05)$ in the motor neuron disease patients. There was no correlation of the spinal level of either of these elements with age in the control group, duration of disease in the patient group or with the levels in liver or bone. The cord:liver ratios were also compared for each of these elements but again no statistically significant differences were found.

No difference between the two groups was shown for the spinal or hepatic levels of any of the other elements studied. Inspection of the data suggested that the cobalt content of the spinal cord might have been increased in the motor neuron disease patients but this was not statistically significant. No differences were found for the bone levels of any of the elements.

\section{Discussion}

As with any study of this type the acquisition of 


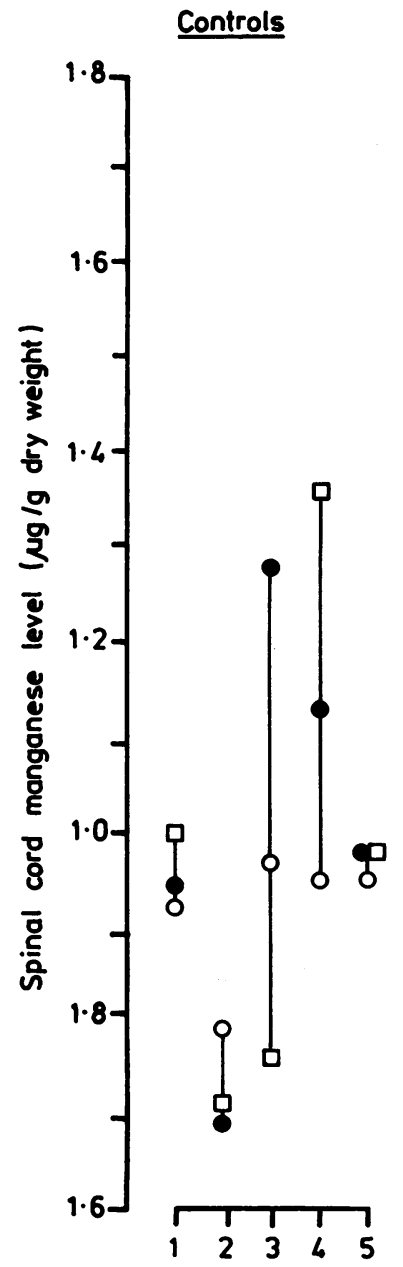

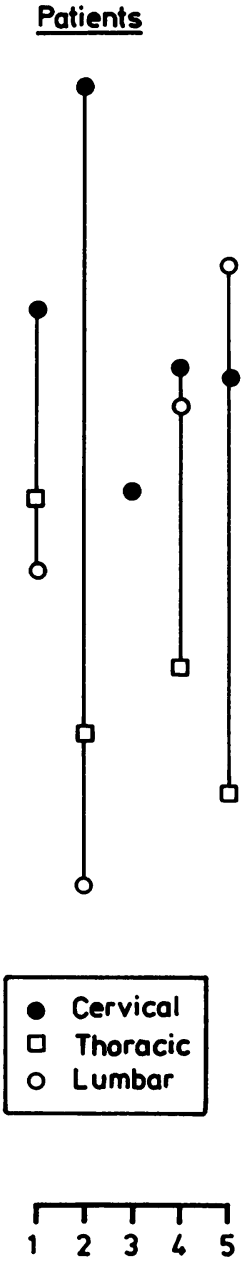

Fig 1 Levels of manganese in the spinal cord.

patient and control material is slow and the analysis time consuming. This is reflected in the small numbers of subjects in each group. Despite this, differences between the two groups have been shown for two elements in spinal cord and one in liver at the highest significance levels possible for these numbers. These findings are of interest with regard both to our understanding of the pathogenesis of motor neuron disease and the report of a reduced CSF cobalt level.

An increased spinal cord manganese level $(p<$ 0.01 ) was recently reported in six control subjects compared with seven motor neuron disease patients. ${ }^{19}$ A previous report using a different method was only able to measure manganese in two patients and one control subject and although the anterior horn tissue manganese level was higher in the patients this clearly was not statistically significant. ${ }^{12}$

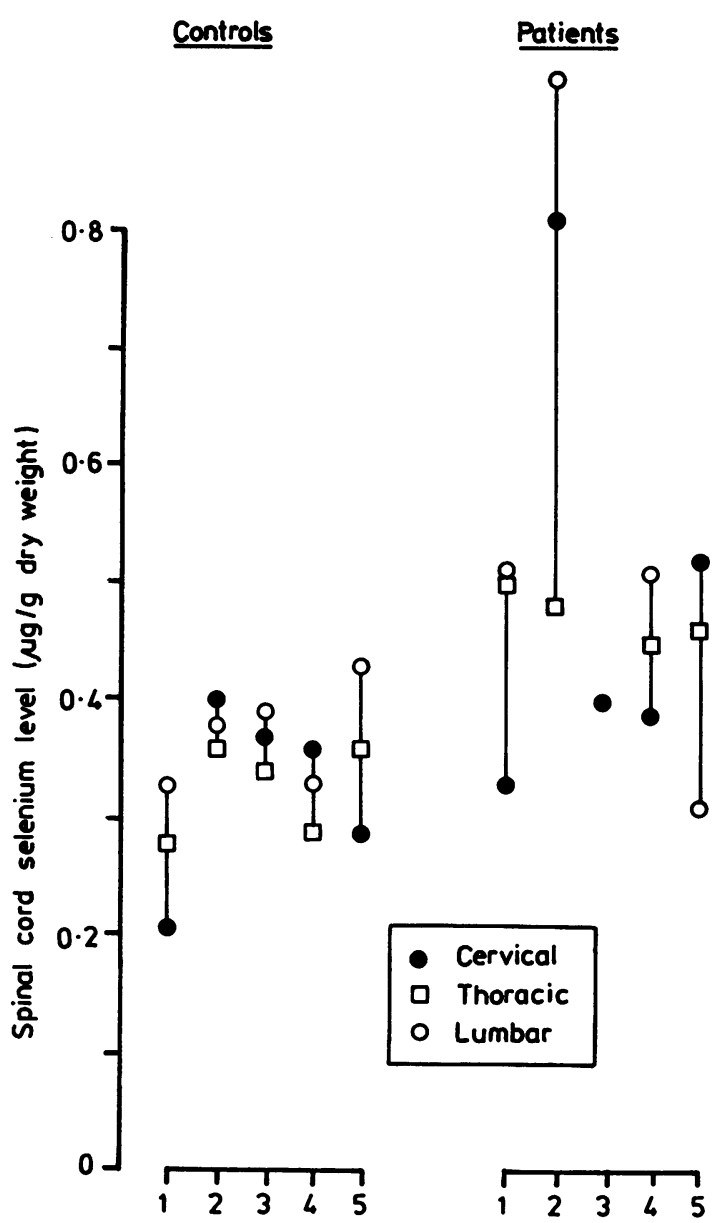

Fig 2 Levels of selenium in the spinal cord.

Interest in selenium in relation to motor neuron disease arose from a report of a cluster of four cases from a selenium rich area of South Dakota. ${ }^{20}$ Subsequent workers failed to demonstrate a difference in urinary selenium levels between motor neuron disease patients and controls ${ }^{21}$ and selenium was only detected in the anterior horn tissue of one out of seven motor neuron disease patients and three out of seven controls. ${ }^{12}$ On this basis it has been considered that there is no evidence to link selenium with motor neuron disease but inspection of the data obtained by this group shows that the selenium level in the motor neuron disease patient was higher than in any of the controls, although again the numbers did not allow statistical analysis.

Unfortunately it was not possible to estimate manganese in the previous CSF study, and selenium was 
only detected in the CSF of one motor neuron disease patient and four control subjects. ${ }^{22}$ There was no evidence to suggest a difference in the selenium content of the CSF in motor neuron disease.

It is interesting that of the many elements studied only these two, manganese and selenium, show significant differences between the two groups. Both elements are implicated in the degradation of free radicals, selenium as a constituent of glutathione peroxidase and manganese as a variable component of superoxide dismutase. It is possible that the increased selenium and manganese levels might represent increased activity of these two enzymes in motor neuron disease and thus reflect free radical accumulation particularly in the spinal cord. Increased free radical production has been implicated in a number of degenerative disorders and is thought to be important in the ageing process. It may be that free radical accumulation mediates the premature degeneration of motor neurons seen in motor neuron disease.

Manganese is also important in nucleic acid metabolism. It plays a role in RNA synthesis as an activating factor for RNA polymerase and although manganese seems to improve fidelity with respect to recognition of complementary bases, it also increases the error incorporation of deoxynucleotides into RNA. In common with other divalent ions, manganese also has the capacity to bind to specific loci in polynucleotides. ${ }^{23}$ These considerations are obviously important in relation to previous reports of an abnormality of nucleic acid metabolism in motor neuron disease and the results described here.

The results of this work in conjunction with the previously reported CSF study ${ }^{1822}$ provide a new angle in our attempts to understand the pathogenesis of this disorder. They provide support for an underlying disorder of DNA transcription, but also suggest that it would be of interest to study free radicals in motor neuron disease. We are currently pursuing some of these implications and aim to study the distribution of trace elements within the nervous system in larger numbers of patients with this enigmatic disease.

We thank Miss Joan Lennie for her help in the preparation of the manuscript; Dr A Gordon, Dr JN Webb and Dr MA McIntyre of the Departments of Neuropathology and Pathology, Western General Hospital, Edinburgh, for assistance in obtaining specimens; Wolfson Laboratory, Western General Hospital for freeze-drying the samples; Dr EH Jellinek and Dr B Ashworth and the physicians of the Western General Hospital for allowing us to study patients who had been under their care.
References

${ }^{1}$ Darwall J. Cases of a peculiar species of paralysis. London Medical Gazette 1831;7:201-3.

${ }^{2}$ Bell C. The Nervous System of the Human Body. 3rd Ed. London Longmans: 1836.

${ }^{3}$ Aran FA. Recherches sur une maladie non encore decrite du systeme musculaire. Arch Gen Med (4me Ser) 1850;24:1-35.

${ }^{4}$ Romberg MH. Lehrbuch der Nervenkrankheiten des Menschen. Berlin: Dunker 1851; Trans \& Ed. Sieveking. London: New Sydenham Society 1853; 371-5.

${ }^{5}$ Campbell AMG. Calcium versenate in motor neurone disease. Lancet 1955;2:376-7.

${ }^{6}$ Campbell AMG, Williams ER, Barltrop D. Motor neurone disease and exposure to lead. $J$ Neurol Neurosurg Psychiatry 1970;33:877-85.

${ }^{7}$ Livesley B, Sissons SE. Chronic lead intoxication mimicking motor neurone disease. Br Med J 1968;4:387-8.

${ }^{8}$ Simpson JA, Seaton DA, Adams JF. Response to treatment with chelating agents of anaemia, chronic encephalopathy, and myelopathy due to lead poisoning. J Neurol Neurosurg Psychiatry 1984;27:536-41.

${ }^{9}$ Barber TE. Inorganicmercury intoxication reminiscent of amyotrophic lateral sclerosis. J Occupat Med 1978; 20:667-9.

${ }^{10}$ Adams CR, Ziegler DK, Lin JT. Mercury intoxication simulating amyotrophic lateral sclerosis. JAMA 1983; 250:642-3.

${ }^{11}$ Petkau A, Sawatzky A, Hillier CR, Hoogstraten J. Lead content of neuromuscular tissue in amyotrophic latera sclerosis-case report and other considerations. $\mathrm{Br}$ Indust Med 1974;31:275-87.

${ }^{12}$ Kurlander HM, Patten BM. Metals in spinal cord tissue of patients dying of motor neuron disease. Ann Neurob 1979;6:21-4.

${ }^{13}$ Mandybur TI, Cooper GP. Increased spinal cord lea content in amyotrophic lateral sclerosis-possibly a. secondary phenomenon. Medical Hypotheses 1979; 5:1313-5.

${ }^{14}$ Mann PMA, Yates PO. Motor neuron disease-the nature of the pathogenic mechanism. J Neurol Neurosurg Psychiatry 1974;37:1036-46.

${ }^{15}$ Davidson TJ, Hartmann HA. RNA content and volume of motor neurones in amyotrophic lateral sclerosis. $J$ Neuropath Exp Neurol 1981;40:187-92.

${ }^{16}$ Davidson TJ, Hartmann HA. Base composition of RNA obtained from motor neurones in amyotrophic lateral sclerosis. J Neuropath Exp Neurol 1981;40:193-8.

${ }^{17}$ Bradley WG, Krasin F. A new hypothesis of the etiology of amyotrophic lateral sclerosis. Arch Neurol 1982;39:677-80.

${ }^{18}$ Mitchell JD, Harris IA, East BW, Pentland B. Trace elements in cerebrospinal fluid in motor neurone disease. Br Med J 1984;288:1791-2.

${ }^{19}$ Miyata $S$, Nakamura S, Nagata $H$, Kameyama $M$. Increased manganese level in spinal cords of amyotrophic lateral sclerosis determined by radiochemical neutron activation analysis. $J$ Neurol Sci 1983;61:283-93.

${ }^{20}$ Kilness AW, Hochberg FH. Amyotrophic lateral sclerosis in a high selenium environment. JAMA 1977;237: 2843-4. 
${ }^{21}$ Norris FH, U KS. Amyotrophic lateral sclerosis and low urinary selenium levels. JAMA 1978;239:404.

${ }^{22}$ Mitchell JD, Harris IA, East BW, Pentland B. Cerebrospinal fluid trace elements in motor neurone disease-cobalt content is reduced. In: Mills CF ed. Trace Element Metabolism in Man and Animals, Vol 5,
1984. In Press.

${ }^{23}$ Marzilli LG, Kirstenmacher TJ, Eichhorn GL. Structural principles of metal ion-nucleotide and metal ion-nucleic acid interactions. In: Spiro TG. ed. Nucleic Acid-metal Ion Interactions, New York. John Whiley \& Sons 1980. 